\title{
Coconut husk ash as heterogenous catalyst for biodiesel production from cerbera manghas seed oil
}

\author{
Husni Husin ${ }^{1,}{ }^{*}$, Abubakar Abubakar ${ }^{1}$, Suci Ramadhani $^{1}$, Cici Ferawati Br. Sijabat ${ }^{1}$, and Fikri Hasfita ${ }^{2}$ \\ ${ }^{1}$ Syiah Kuala University, Department of Chemical Engineering, Darussalam, 23111, Banda Aceh, Indonesia \\ ${ }^{2}$ Malikussaleh University, Department of Chemical Engineering, Lhoekseumawe, 24300, Aceh Utara, Indonesia
}

\begin{abstract}
The research on the use of coconut husk as a solid catalyst for transesterification reaction of Cerbera manghas oil into biodiesel has been done. The aim of this study is to investigate the performance of coconut husk ash for biodiesel production from Cerbera manghas seed oil. Coconut husk is prepared by burning in air to obtain potassium oxide as active phase. The coconut husk is analyzed by X-ray diffraction (XRD) and scanning electron microscopy (SEM). The XRD spectrum shows that the peak characteristics of potassium oxide can be observed in the diffractogram. The particle size of the catalyst ranging from $1-3$ $\mu \mathrm{m}$ with pentagonal structure. The coconut husk ash solid catalyst is used in the transesterification reaction of Cerbera manghas oil in a batch reactor. Biodiesel yield of $88.6 \%$ can be achieved over coconut husk ash catalyst, using a $10 \mathrm{wt} . \%$ of catalyst, reaction temperature at 3 hours, and a methanol-to-oil ratio of 6: 1. This solid catalyst can be separated easily from the reaction system and not soluble in methanol or methyl esters. The coconut husk ash catalyst is high potential to be developed as one of the solid catalysts to convert Cerbera manghas oil to biodiesel.
\end{abstract}

\section{Introduction}

Nowadays, energy and chemicals are produced from fossils source. Energy and environmental problems elevated by the usage and potential depletion of fossil fuels stimulate research on the new energy sources [1-6]. The increase in population and industrial development has accelerated the exploration of renewable clean energy resources such as hydrogen energy [7-8], solar energy [9-10], and biodiesel [11].

Biodiesel is considered to be one of the best alternative fuel candidates as a substitute for diesel because it can be used as a blend in a conventional diesel engine without modification of the engine. Biodiesel from vegetable oil is a renewable, clean, and environmentally friendly energy [12-14]. Transesterification is the most widely used method commercially for biodiesel production between vegetable oils with alcohols [15]. Transesterification can be catalyzed by either a homogeneous catalyst (acid or base) or a heterogeneous catalyst [16].

Literary studies report that the use of basic catalysts is highly sensitive to water and free fatty acids present in vegetable oils. Vegetable oil needs to be purified before the transesterification reaction takes place and the separation of the product is so difficult that it requires additional refining costs. The use of liquid acid catalysts such as $\mathrm{H}_{2} \mathrm{SO}_{4}$ requires high temperatures and relatively long reaction times and may harm the environment. Additionally, a homogenous catalyst, operating batch requires expensive operating costs [17-20].
Various types of heterogeneous catalysts have been applied to the transesterification process, such as alkaline earth metal oxides, alkali metals of various compounds in support of alumina or zeolite [21-22]. This catalyst is more stable and environmentally friendly. Many solid basic catalysts such as La:Mn/Cinder [23], $\mathrm{CaO}$ [24], and $\mathrm{KOH} /$ Zeolite [25] have been used for biodiesel production [26-27]. However, some of the proses required high reaction temperature. This research was carried out the synthesis of ash as a solid catalyst from coconut husk by the simple burning method. Then, the prepared ash was applied in transesterification reaction of Cerbera manghas oil into biodiesel.

The purpose of this work is to obtain an active and low cots solid catalyst from coconut husk ash for transesterification of Cerbera manghas oil for biodiesel production

\section{Experimental}

\subsection{Materials}

The solid catalyst used in this work was made from coconut husk. Coconut husk and cerbera manghas oil were collected from land around the Syiah Kuala University Campus, Banda Aceh, Indonesia. All the chemicals used in this research were of analytical grade purity. Methanol were purchased from Merck (99.5\%), Darmstadt, Germany.

\footnotetext{
* Corresponding author: husni husin@.che.unsyiah.ac.id
} 


\subsection{Catalyst preparation}

Coconut husk were chosen as a raw material for the production of ask catalyst, because of their availability in a large quantity. After coconut harvesting, the husk was separated from coconut shell. Thus, the obtained coconut husk was dried. Then, the resulting ash powder was cooled by mortar. It was used as catalyst for transesterification of cerbera manghas oil.

\subsection{Catalyst characterization}

The structural characteristics of the coconut husk ash catalyst particles were characterized by using X-ray diffractometer (Shimadzu XRD-600, $30 \mathrm{kV}, 30 \mathrm{~mA}$ with $\mathrm{Cu} \mathrm{K} \alpha$ radiation, $1.5418 \AA$ ). SEM imaging were conducted on a Philips XL-30, operating with accelerating voltage of $15 \mathrm{kV}, 70 \mathrm{~Pa}$.

\subsection{Transesterification reaction}

Cerbera manghas oil (CMO) of $100 \mathrm{~g}$ and the catalyst approximately $10 \mathrm{wt} . \%$ to $\mathrm{CMO}$ were introduced into the reactor. This reactor is equipped with a condenser to avoid methanol evaporation during the process. The methanol-to-oil ratio of $6: 1$ and the temperature was keep at $60{ }^{\circ} \mathrm{C}$. After stirring for 3 hours the transesterification was stop, the catalyst was separated from the mixture by centrifugation during 0.5 hours. The reaction mixture was transferred to a separating funnel and washed with hot water, which allows decantation and separation of glycerol and methyl esters. The methyl ester was transferred into a vacuum rotary evaporator to remove the remaining methanol. The methyl esters were dried at $110{ }^{\circ} \mathrm{C}$ in an oven to remove traces of water. Analysis of the products was performed using on a Shimadzu gas chromatograph equipped with a mass spectrophotometry (GC-MS).

\section{Results and discussion}

\subsection{XRD and SEM of coconut husk ash catalyst}

Fig. 1. shown the XRD patterns of coconut husk ash (CHA) catalyst. The CHA pattern demonstrated the formation of potassium oxide $\left(\mathrm{K}_{2} \mathrm{O}\right)$ crystals, as depicted in Fig. 1. As can be seen in the XRD pattern, there are also some minor peak were recorded as unknown compound. According to JCPDS card no. 26-1327, the characteristic peaks of $\mathrm{K}_{2} \mathrm{O}$ appear at $2 \theta: 25.121^{\circ}$, $28.807^{\circ}$, and $40.625^{\circ}$, respectively. It indicates that the potassium oxide phase was formed during the burning process.

To get further insight on the morphology of coconut husk ash samples, a SEM study was also carried out, as shown in Fig. 2. The SEM of powdered of coconut husk ash clearly exhibited in an irregular pattern.

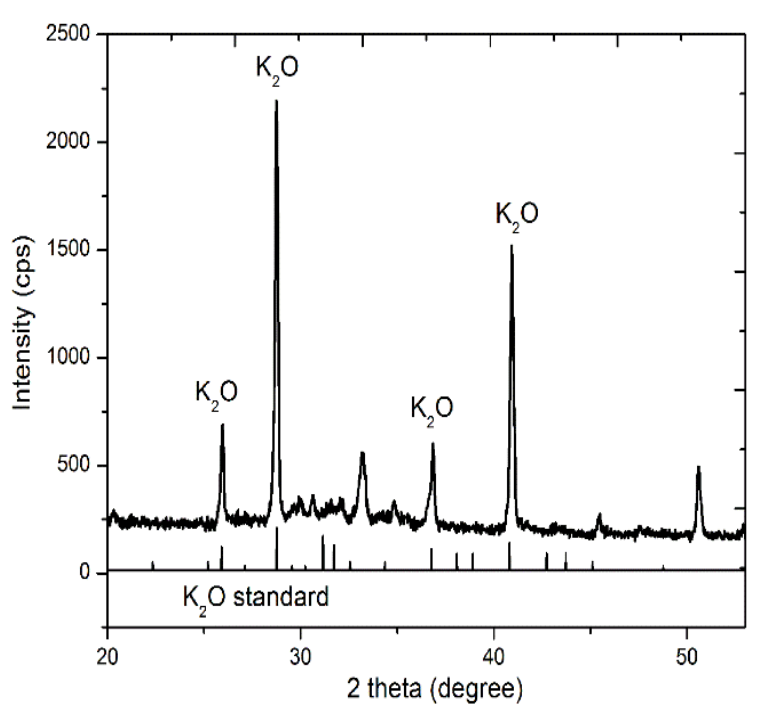

Fig. 1. XRD pattern of coconut husk ash catalyst.

The coconut husk ash sample is composed by large particles, which sizes ranged 1-3 $\mu \mathrm{m}$. It's also shown of some particle exposing a pentagonal structure, by having a very well define texture with heterogeneous surface channels.

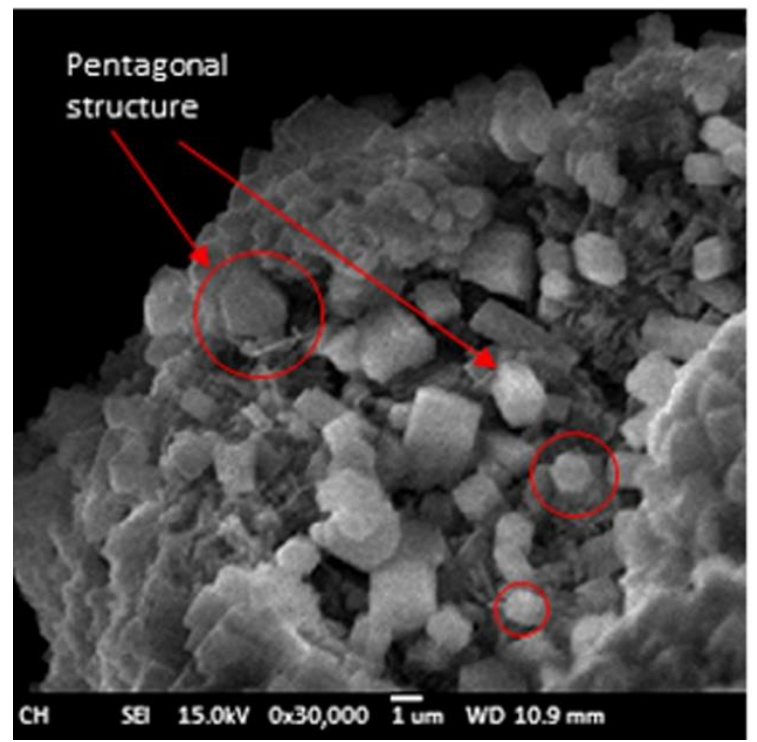

Fig. 2. SEM images of coconut husk ash catalyst.

These morphological features could effectively possess basic surface sites, which make them highly efficient in catalytic process in applications for transesterification of Cerbera manghas oil into biodiesel [28].

\subsection{Effect of catalyst loading on biodiesel yield}

The catalyst loading is very crucial step in the availability of active sites on the reaction system which provides specific surface area of catalyst. The effect of catalyst amount on its activity was illustrated in Fig. 3. 


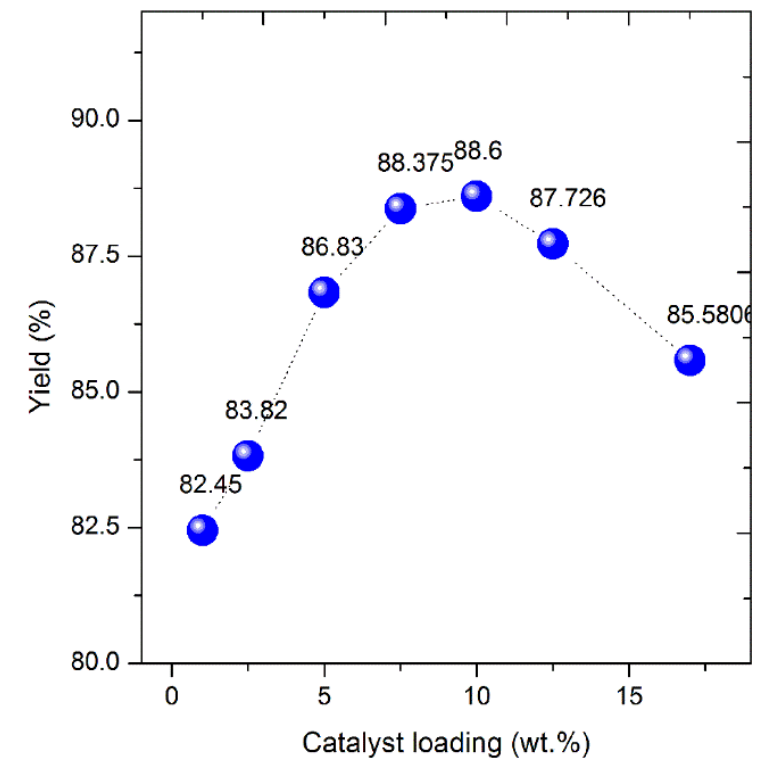

Fig. 3. Effect of catalyst loading on biodiesel.

It shows that Cerbera manghas oil conversion was greatly dependent on catalyst loading. Biodiesel production increased significantly by increasing the amount of catalyst from 1 to $10 \%$. However, when increasing the amount of catalyst loading more than $12.5 \%$, the slurry became too viscous giving rise to a problem of mixing, the biodiesel yield could not be maximum [29]. The optimum catalyst loading amount was found to be $10.0 \%$ in this system and the methyl ester yield reaches of 88.6 wt.\% during $3 \mathrm{~h}$. Loading catalyst is very effecting to increase catalytic activity at certain condition. If the amount is in the right portion then the production can be maximize [30-32]. The burning process of the coconut husk play an important role in forming an active component of the catalyst. It is evident that high crystallinity of the catalyst results in high catalytic performance.

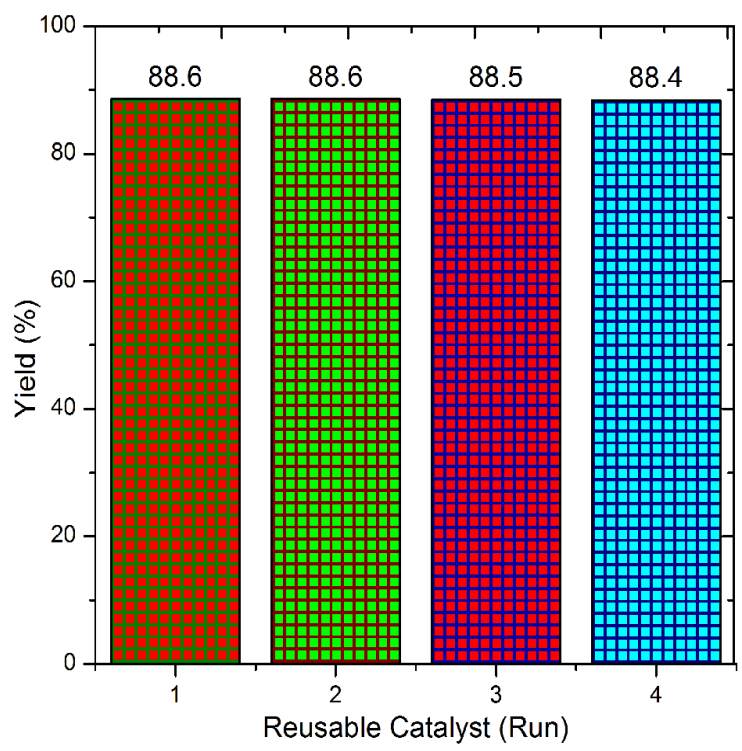

Fig. 4. Effects of reuse catalyst.
Fig. 4 describes the influence of the recycling process on the yield of biodiesel. As depicted in Fig. 4, the catalytic activity of coconut husk ash remained impressively stable upon successive reuses, with no appreciable loss in catalytic activity. The catalyst could be treated just by simple heating in an oven at $100{ }^{\circ} \mathrm{C}$. The heated catalyst could be reused for several times with more than $88 \%$ of biodiesel reached within 3 $\mathrm{h}$. The biodiesel composition and physicochemical characterization of the cerbera manghas seed oil are shown in Table 1 and 2. As demonstrated in Table 1, the highest components are methyl palmitate, and methyl elaidate. From Table 1, it is reported that methyl palmitate is the highest concentration of $36.96 \%$. The other component also composed of methyl linoleate, methyl oleate, and methyl stearate.

Table 1. Composition of biodiesel obtained from cerbera manghas oil.

\begin{tabular}{|c|c|c|}
\hline No. & Methyl ester & $\begin{array}{c}\text { Composition } \\
(\%)\end{array}$ \\
\hline 1 & Methyl Palmitate & 36.96 \\
\hline 2 & Methyl Linoleate & 13.60 \\
\hline 3 & Methyl Elaidate & 32.57 \\
\hline 4 & Methyl Oleate & 10.79 \\
\hline 5 & Methyl Stearate & 7.06 \\
\hline
\end{tabular}

The properties kinematic viscosity, density, and and the acid number conformed to the ASTM specifications. The properties of obtained biodiesel from the cerbera manghas oil is rated as a realistic fuel as an alternative to diesel fuels.

Table 2. Properties of biodiesel.

\begin{tabular}{|c|c|c|c|}
\hline Element & This work & ASTM & SNI \\
\hline $\begin{array}{c}\text { Kinematic } \\
\text { viscosity (cSt) }\end{array}$ & $2.5-3.4$ & $2.59-3.4$ & $\begin{array}{c}2.30- \\
6,00\end{array}$ \\
\hline $\begin{array}{c}\text { Density } \\
\left(\mathrm{gr} / \mathrm{cm}^{3}\right)\end{array}$ & $0.85-0,865$ & $\begin{array}{c}0,80- \\
0,88\end{array}$ & $\begin{array}{c}0.85- \\
0.89\end{array}$ \\
\hline $\begin{array}{c}\text { Acid number } \\
(\mathrm{mg} \mathrm{KOH} / \mathrm{gr})\end{array}$ & $0.11-0.41$ & $\max 0.80$ & $\max 0.80$ \\
\hline
\end{tabular}

\section{Conclusions}

The coconut husk ash solid catalyst has been synthesized by the simple burning method. From the XRD result shown that the catalysts were composed of potassium oxide $\left(\mathrm{K}_{2} \mathrm{O}\right)$ crystalline. The performed of the coconut husk ash was evaluated by esterification reaction of Cerbera manghas oil. It was found that the best conditions to reaches a high biodiesel yield of $88.6 \%$ are $10 \mathrm{wt} . \%$ of catalyst, reaction temperature at 3 hours, and a methanol-to-oil ratio of $6: 1$. The coconut husk ash catalyst is active for 4 consecutive reaction, with more than $88 \%$ of biodiesel reached within $3 \mathrm{~h}$. The properties of produced biodiesel were compared with the ASTM standards, the density, kinematic viscosity, and acid number in the range of the ASTM specifications. Coconut husk ash catalyst displays high potential as solid catalyst for practical application. 
This work was supported by the Syiah Kuala University, Republic of Indonesia through the Research Grants of Professor 2018.

\section{References}

1. Abdullah, R.N. Rahmawati Sianipar, D. Ariyani, I.F. Nata, Sustainable Environment Research 27 (6), 291-295 (2017)

2. M.R. Hani, M. Mahidin, H. Husin, H. Hamdani, K. Khairil, IOP Conference Series: Materials Science and Engineering 334 (1), 012003 (2018)

3. S.H.Y.S. Abdullah, N.H.M. Hanapi, A. Azid, R. Umar, H. Juahir, H. Khatoon, A. Endut, Renewable and Sustainable Energy Reviews 70, 1040-1051 (2017)

4. S. Boonyuen, S.M. Smith, M. Malaithong, A. Prokaew, B. Cherdhirunkorn, A. Luengnaruemitchai, Journal of Cleaner Production 177, 925-929 (2018)

5. H. Husin, M. Marwan, Reaktor 8 (1), 37-42 (2017)

6. R. Mardian, H. Husin, K. Pontas, M. Zaki, T. M. Asnawi, Ahmadi, IOP Conference Series: Materials Science and Engineering 334 (1), 012013 (2018)

7. H. Husin, P.N. Alam, M. Zaki, Sofyana, Jakfar, Husaini, F. Hasfita, IOP Conference Series: Materials Science and Engineering 345 (1), 012003 (2018)

8. H. Husin, K. Pontas, Y. Sy, S. Syawaliah, S. Saisa, Journal of Engineering and Technological Sciences 46 (3), 318-327 (2014)

9. H. Husin, M. Mahidin, Y. Yunardi, F. Hafita, Key Engineering Materials 659, 231-236 (2015)

10. H. Husin, M. Mahidin, Z. Zuhra, F. Hafita, Bulletin of Chemical Reaction Engineering \& Catalysis 9 (2), 81-86 (2014)

11. M. Mahlinda, H. Husin, M. Riza, Jurnal Teknologi Industri Pertanian 26 (3), 294-300 (2017)

12. J. Wang, L. Yang, W. Luo, G. Yang, C. Miao, J. Fu, S. Xing, P. Fan, P. Lv, Z. Wang, Fuel 196, 306-313 (2017)

13. A. Guldhe, C. V. R. Moura, P. Singh, I. Rawat, E. M. Moura, Y. Sharma, F. Bux, Renewable Energy 105, 175-182 (2017)

14. I.B. Banković-Ilić, M.R. Miladinović, O.S. Stamenković, V.B. Veljković, Renewable and Sustainable Energy Reviews 72, 746-760 (2017)

15. C. Huang, A.J. Ragauskas, X. Wu, Y. Huang, X. Zhou, J. He, C. Huang, C. Lai, X. Li, Q. Yong, Bioresource Technology 250, 365-373 (2018)

16. H. Husin, Adisalamun, Y. Sy, T.M. Asnawi, F. Hasfita, AIP Conference Proceedings 1788 (1), 030073 (2017)

17. B. Rahmani Vahid, M. Haghighi, Energy Conversion and Management 134, 290-300 (2017)

18. H. Husin, T.M. Asnawi, A. Firdaus, H. Husaini, I. Ibrahim, F. Hasfita, IOP Conference Series:
Materials Science and Engineering 358 (1), 012008 (2018)

19. J. Gardy, A. Hassanpour, X. Lai, M.H. Ahmed, Applied Catalysis A: General 527, 81-95 (2016)

20. A.K. Yadav, M.E. Khan, A. Pal, B. Singh, Biofuels 9 (1), 101-112 (2018)

21. H. Husin, Zuhra, F. Hasfita, W. Rinaldi, The Annual International Conference Syiah Kuala University, 3 (1) (2013)

22. O. Nur Syazwani, U. Rashid, Y.H. Taufiq Yap, Energy Conversion and Management 101, 749-756 (2015)

23. S. Nasreen, M. Nafees, M.M. Jaffar, L.A. Qurashi, S. Tabraiz, R. khan, International Journal of Hydrogen Energy 42, 18389-18396 (2017)

24. Z. Zuhra, H. Husin, F. Hasfita, W. Rinaldi, Agritech 35 (1), 69-77 (2015)

25. N. Fitriana, H. Husin, D. Yanti, K. Pontas, P. N. Alam, M. Ridho, Iskandar, IOP Conference Series: Materials Science and Engineering 334 (1), 012011 (2018)

26. T. Fazal, A. Mushtaq, F. Rehman, A. Ullah Khan, N. Rashid, W. Farooq, M.S.U. Rehman, J. Xu, Renewable and Sustainable Energy Reviews 82, 3107-3126 (2018)

27. M. Farooq, A. Ramli, A. Naeem, T. Mahmood, S. Ahmad, M. Humayun, M.G.U. Islam, Chemical Engineering Research and Design 132, 644-651 (2018)

28. Q. Fengxian, L. Yihuai , Y. Dongya , L. Xiaohua, S. Ping, Bioresource Technology 102 (5), 4150-6 (2011)

29. Mahlinda, H. Husin, M.D. Supardan, M. Riza, A. Muslim, Journal of Engineering Science and Technology 12 (12), 3412-3425 (2017)

30. I. Istadi, D.D. Anggoro, L. Buchori, D.A. Rahmawati, D. Intaningrum, Procedia Environmental Sciences. 23, 385-393 (2015)

31. H. Husin, S.W. Nien, P.C. Jern, L.J. Yue, R. John, Y.S. Chiang, C.W. Tsung, S.H. Shuenn, H.B. Joe, International Journal of Hydrogen Energy 38 (31), 13529-13540 (2013)

32. H. Husin, W.N. Su, H.M. Chen, C.J. Pan, S.H. Chang, J. Rick, W.T. Chuang, H.S. Sheu, B.J. Hwang, Green Chem. 13 (7), 1745 -1754 (2011) 